ISSN 2306-1561

Automation and Control in Technical Systems (ACTS)

2014, No 1.1(8), pp. 112-121.

DOI: $10.12731 / 2306-1561-2014-1-12$

\title{
Software package for assessing the capacity of gas in underground storage system based on PSIControl
}

\section{Evseev Dmitry Yur'evich}

Russian Federation, engineer of development and realization of complex projects department. JSC "AtlanticTransgasSystem", 109388, Russian Federation, Moscow, Polbina street, 11, Tel.: +7 (495) 660-0802, ext. 628. http://www.atgs.ru

\section{Evseev@atgs.ru}

\begin{abstract}
The paper considers the solution of gas flows and bandwidth of terrestrial technological complex of underground gas storage evaluation at varying target conditions, implemented within the supervisory control module framework of information \& control production system.
\end{abstract}

Keywords: underground gas storage, program complex, gas bandwidth evaluation, simulator, ground-based technological complex, design scheme. 
ISSN 2306-1561

Автоматизация и управление в технических системах (АУТС) 2014. - №1.1(8). - C. 112-121.

DOI: $10.12731 / 2306-1561-2014-1-12$

УДК 004.9:681.3

\section{Программный комплекс оценки пропускной способности газа в подземных хранилищах на базе системы PSIControl}

\section{Евсеев Дмитрий Юрьевич}

Российская Федерация, инженер отдела развития и реализации комплексных проектов. ЗАО "АтлантикТрансгазСистема", 109388, Российская Федерация, г. Москва, ул. Полбина, 11, Тел.: +7 (495) 660-0802, доб. 628. http://www.atgs.ru

Аннотация. В статье рассмотрено решение задачи оценки потоков газа и пропускной способности наземного технологического комплекса подземного хранилища газа при варьируемых целевых условиях, реализованное в рамках модуля диспетчерского управления информационно-управляющей системы производства.

Ключевые слова: подземное хранилище газа, программный комплекс, пропускная способность газа, математическая модель, наземный технологический комплекс, расчётная схема.

\section{1. Введение}

Подача газа потребителям в различные периоды года неравномерна. Для сглаживания сезонных пиковых нагрузок потребления газа используются подземные хранилища газа (ПХГ), которые также предотвращают перебои в поставках в случаях аварий и других непредвиденных обстоятельств в газотранспортной сети и обеспечивают хранение стратегически важных резервов природного газа [1 - 7].

ООО "Газпром ПХГ" имеет 19 филиалов по всей России - Управлений ПХГ (УПХГ) и Производственно-диспетчерское управление (ПДУ), расположенное в Москве, которое осуществляет диспетчерское управление и оперативный контроль режимов работы всех филиалов.

В настоящее время степень автоматизации УПХГ различается - где-то внедрены отдельные АСУТП технологических установок, на нескольких УПХГ реализована единая АСУТП всего технологического комплекса. Эти системы позволяют диспетчерам контролировать текущее состояние и подавать команды управления 
оборудованием. Однако в этих АСУТП до настоящего времени не реализовывалась функция оценки потоков газа и пропускной способности наземного технологического комплекса ПХГ при варьируемых целевых условиях [5 - 20].

В статье рассмотрено решение данной задачи, реализованной в рамках модуля диспетчерского управления (ДУ) информационно-управляющей системы производства OOO "Газпром ПХГ" на базе программного комплекса PSIControl немецкой фирмы PSI AG.

\section{2. Основные проблемы и задачи}

Существует ряд различных факторов, серьёзно влияющих на работу ПХГ, среди которых:

- объем и давление активного газа в хранилище. Данный показатель известен на начало цикла закачки/отбора и его необходимо знать в каждый момент времени. Этот параметр влияет на максимально возможный суточный объем отбора/закачки газа;

- зависимость пропускной способности агрегатов наземного комплекса от планируемых ремонтов оборудования, т.к. при выводе в ремонт оборудования имеется меньшая мощность на прокачку газа.

- зависимость производительности части агрегатов от давления газа на входе. Данный показатель особенно важен в период отбора, когда газа в хранилище становится меньше и давление падает.

Целью данного проектного решения является повышение эффективности процессов производственного планирования работы ПХГ за счет решения следующих задач:

Составления математической модели потоковой схемы применительно к наземной части технологического комплекса ПХГ;

Определение максимальной производительности комплекса, исходя из возможностей подземного хранилища при данном режиме отбора/закачки.

\section{3. Исходные данные}

Помимо созданной математической модели данных в системе используются следующие исходные данные:

- Объем активного газа (АГ) в хранилище на начало периода расчёта (планирования работы ПХГ). Данный параметр определяет максимальную потенциальную возможность отбора газа из хранилища и вводится диспетчером вручную на момент начала периода отбора газа.

- Данные о запланированных ремонтах оборудования. Поступают из внешних систем, в частности из модуля ремонтов PM системы SAP ERP.

- Полином ЦКР. Математическая зависимость значения максимального объема отбора газа от объема активного газа в хранилище. Как правило, является 
полиномом 5-го порядка и вводится в систему с помощью коэффициентов уравнения или «по точкам».

- Зависимость производительности агрегатов. В каждом конкретном случае представляет собой типовую зависимость производительности агрегата от входных параметров (например, давления газа на входе).

\section{4. Виды расчётов в системе}

Программный комплекс выполняет одновременно несколько функций: он служит как инструментом моделирования текущей работы комплекса в целом, так и инструментом анализа и планирования работы в будущем. Поэтому в системе предусмотрено 3 различных вида расчёта:

Расчёт реального времени. При таком виде расчёта используются данные реального времени о текущем состоянии оборудования, поступающие из АСУ ТП или введённые вручную. Производится расчёт максимальной производительности технологического комплекса ПХГ на текущие сутки.

Расчёт на будущее (планирование). При таком виде расчёта используются данные о запланированных ремонтах на будущее (а не текущее состояние оборудования). Объем активного газа пересчитывается рекурсивно на каждые сутки в зависимости от режима за предыдущий период. Расчёт может быть осуществлён на период до 3 лет.

Моделирование. Цель данного типа расчёта - дать диспетчеру возможность самому установить режим работы технологического комплекса. Пользователь может изменить состояние работы оборудования (включить/ выключить), задать собственные ограничения и уставки на производительность отдельных узлов и всего комплекса в целом. Такой может быть осуществлён также на период до 3 лет.

Запуск расчёта осуществляется с помощью контекстного меню с выбором вида расчёта. В появившемся диалоговом окне необходимо выбрать интересующий период расчёта (с какого по какое число) и запустить расчёт (рисунок 1).

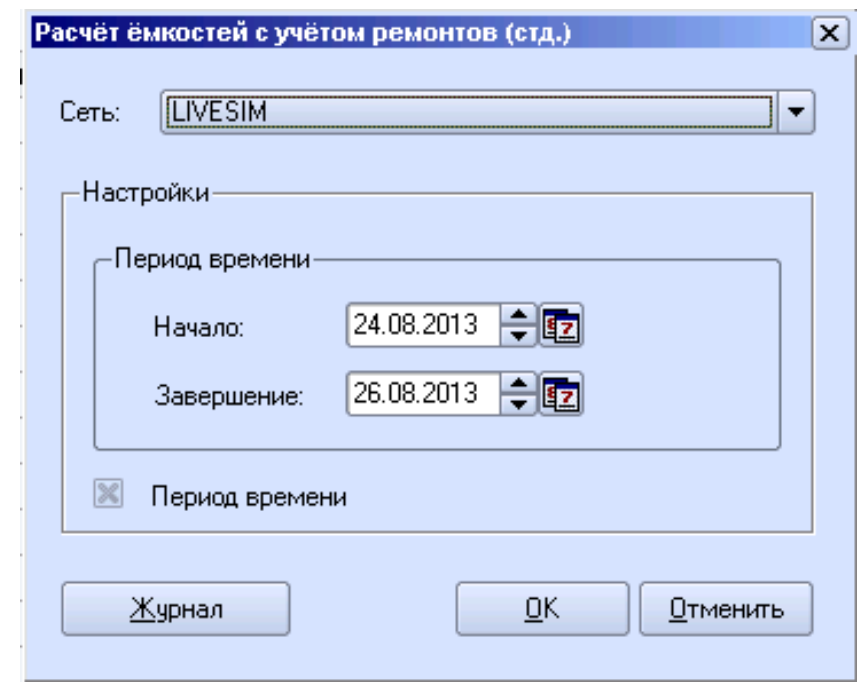

Рисунок 1 - Запуск расчёта 
Результаты расчёта (в т.ч. сообщения об ошибках) записываются в специальный журнал.

\section{5. Расчётная модель}

Если PSIControl - это основная среда визуализации и работы диспетчера, то самим расчётным модулем является PSIStorage. Но стоит заметить, PSIStorage не имеет ни отдельного графического интерфейса, ни отдельной базы данных - результаты расчетов хранятся в объектах БД PSIControl и могут быть обычным образом отображены на мнемосхемах.

Расчётная модель главным образом состоит из двух основных частей:

- подземная часть, которая обуславливается параметрами самого хранилища и объёмом активного газа;

- наземный комплекс, который включается в себя всё наземное оборудование, через которое осуществляется прокачка газа.

Для определения потенциальных возможностей пласта используется зависимость максимального объёма отбора газа от количества активного газа на текущий момент [1 $4,6,7,18,20]$. Эта зависимость представлена в виде математической формулы (как правило, полинома 5-го порядка) и известна заранее. Для её описания в системе предусмотрен отдельный графический интерфейс (рисунок 2).

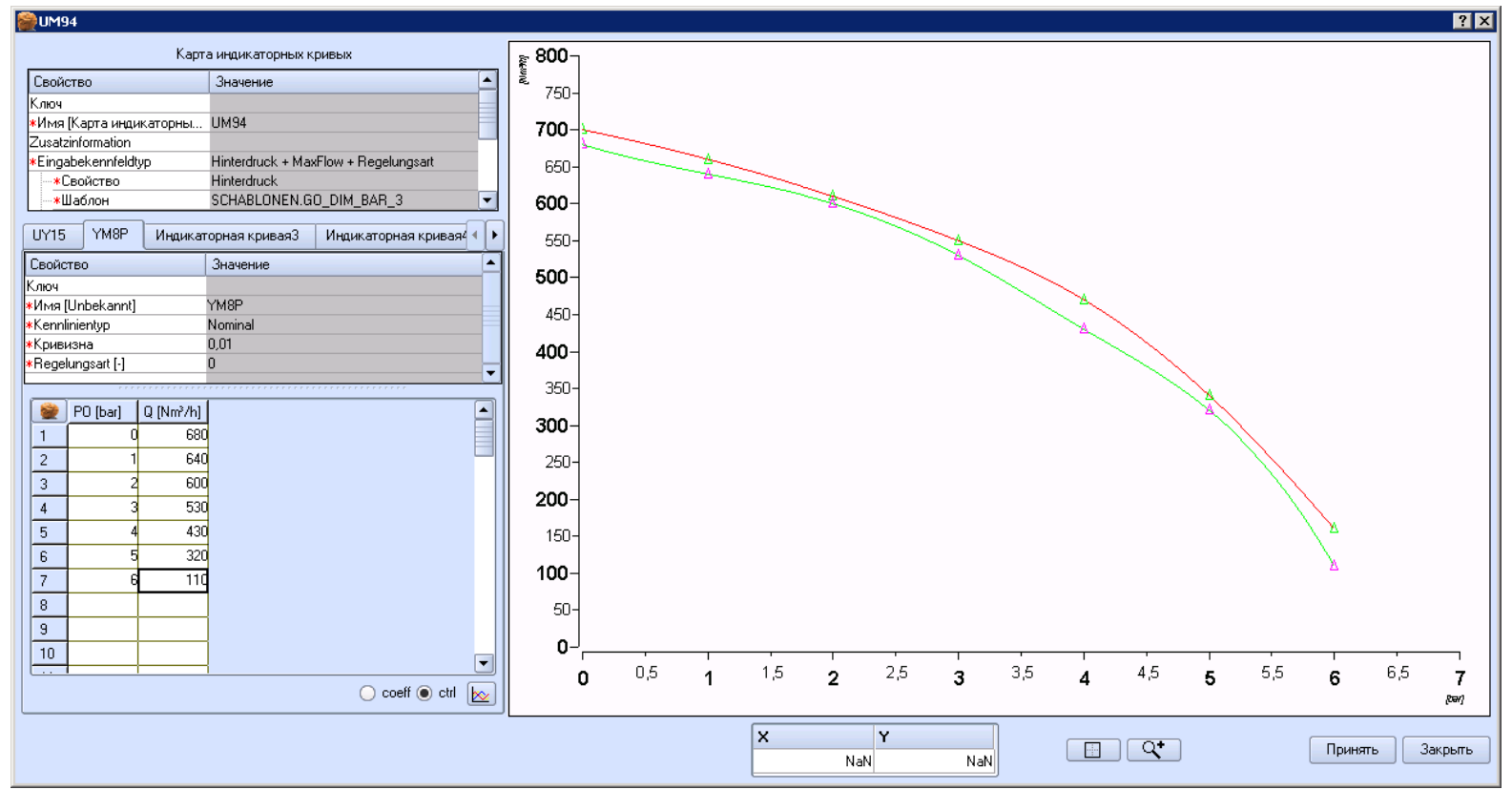

Рисунок 2 - Графическое представление ограничений подземного хранилища

Он позволяет как вводить коэффициенты полиномов, так и вносить табличные значения для построения зависимости по точкам.

Также в качестве исходных данных вводится количество активного газа в хранилище на начало периода - для определения «начальной точки» отсчёта. 
Данная кривая является ограничением потенциальной возможности, а такой режим, как правило, не всегда совпадает реальным. Поэтому на графике есть возможность "параллельно" отображать текущий режим отбора газа. При этом в зависимости от текущего значения активного газа ему сопоставляется новое, пересчитанное значения ограничения отбора газа.

Второй, наиболее сложной частью математической модели, является модель наземного комплекса оборудования.

Если на потенциальные возможности пласта влияет только значение активного газа в хранилище, зависимость которого математически задана, то пропускная способность наземного комплекса зависит от нескольких факторов.

Для расчёта данной величины используется алгоритм Форда - Фалкерсона, решающий задачу нахождения максимального потока в транспортной сети. Таким образом, задача сводится к правильному построению топологии потоковой схемы и определению "сколько можно прокачать" при тех или и условиях.

Как выше было сказано - весь графический интерфейс представлен в модуле PSIControl. Поэтому с помощью встроенного графического редактора можно составлять различные расчётные схемы, соответствующие заданной конфигурации оборудования. Схемы состоят из отдельных элементов, соединённых в одно общую потоковую схему с одним входом и выходом (возможно несколько выходов). Каждый элемент соответствует самостоятельной технологической единице оборудования, имеющей свою пропускную способность (скважины, пылеуловители, сепараторы и т.п.). Такие элементы как краны и задвижки, как правило, отдельно не рассматриваются, так как входят в состав запорной арматуры скважины или, например, сепаратора. При этом важное значение имеет тот факт, что при выводе в ремонт этого самого крана в ремонт будет выведен весь сепаратор.

Данные о согласованных ремонтах из SAP импортируются в систему и учитываются при расчёте. Также Диспетчер может вручную "вывести" интересующее его оборудование, например скважину, в ремонт. Естественно, никакого реального ремонта это не означает, но таким образом можно оценить изменение режима работы и учитывать эти показатели при планировании будущих ремонтов.

На рисунке 3 показана расчётная схема для потока газа на Газораспределительном пункте (ГРП).

На схеме изображены объекты, моделирующие эксплуатационные скважины, пылеуловители и сепараторы. Для каждого из объектов существует MAX и MIN ограничения пропускной способности. Эти значения являются технологическими (паспортными) характеристиками оборудования, некоторые зависят от значений определённых параметров (например, от давления на входе сепаратора), но могут устанавливаться и вручную диспетчером. Это очень важно, т.к. зачастую верхняя граница возможности отбора в разы превышает рекомендуемый режим. 
Ставропольское УПХГ. Хадум. ГРП 7

Режим отбора газа

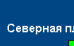

664 677 667 678

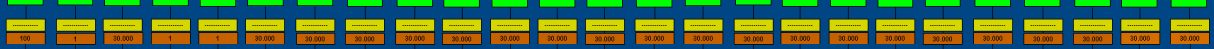
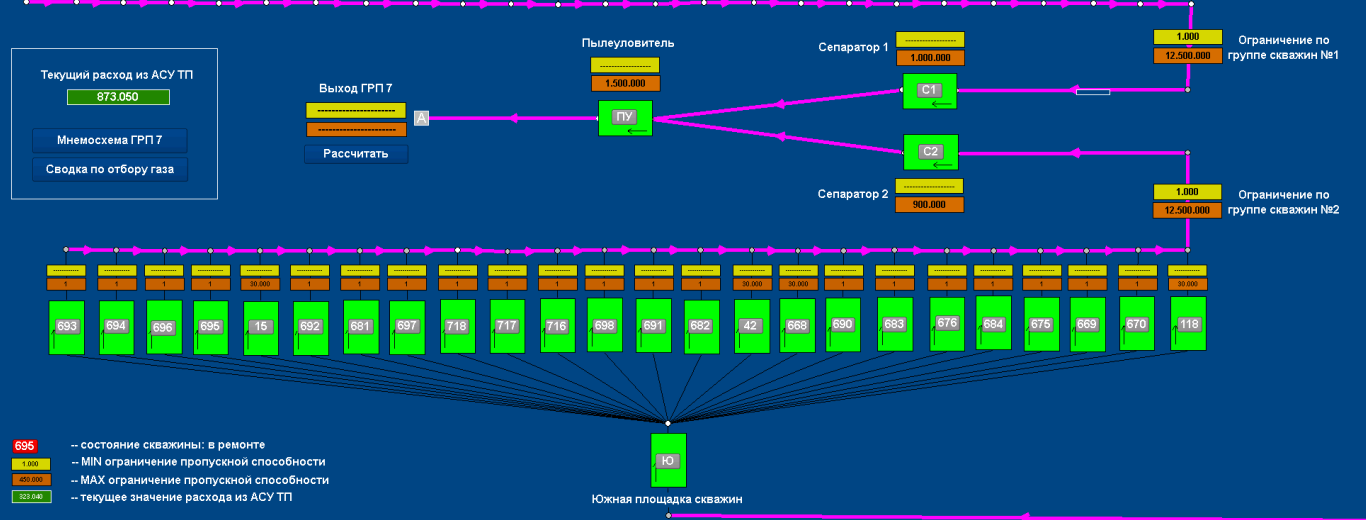

\section{Рисунок 3 - Расчётная схема ГРП}

На рисунке 4 показан подробный фрагмент расчётной схемы ГРП (представленной на рис. 3).

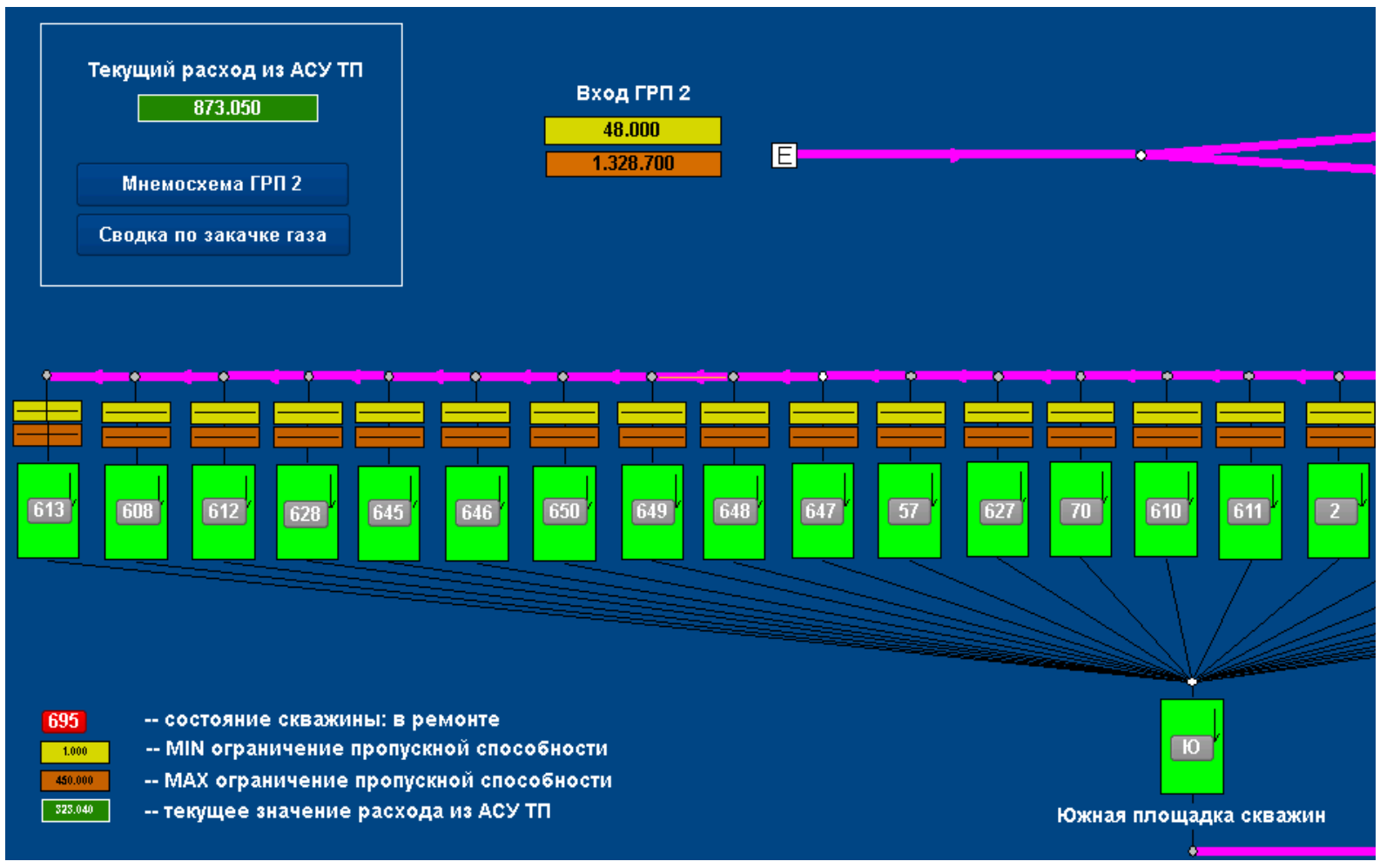

\section{Рисунок 4 - Подробный фрагмент расчётной схемы}

На рисунке 4 видно, что каждый объект (в частности описывающий скважину) имеет индикатор состояния (вкл/выкл) и поля с рассчитанными MAX и MIN ограничениями. 
Также на схему выведен текущий реальный режим работы, а именно расход газа на входе/выходе ГРП. Эти показатели для сравнения выводятся из АСУ ТП филиала (если таковые показатели имеются).

Стоит отметить, что расчётная модель имеет несколько уровней детализации. Дело в том, что объект хранения, как правило, эксплуатируется несколькими сборными пунктами (или ГРП) и результаты расчёта схемы уровня ГРП будут являться исходными данным для расчёта пропускной способности объекта хранения в целом. Кроме того, иногда есть необходимость смоделировать ситуацию вывода ГРП целиком, а не отдельных скважин (на пример, при реконструкции ГРП). Поэтому у Диспетчера есть возможность вывести весь комплекс ГРП в ремонт, не вдаваясь в подробности его состава и отдельных ограничений.

Так, например, как видно из рисунков 3 и 4, на схеме предусмотрен объект "Южная площадка скважин", вывод которого будет означать вывод всех вышестоящих скважин в ремонт. При этом состояние каждой отдельно взятой скважины не поменяется и не будет потеряно, просто будет исключено из расчёта.

Таким образом, сопоставляя два результата расчёта (ограничение подземной части и пропускной способности наземного комплекса), которые представляют собой два последовательных звена глобальной потоковой схемы, мы выбираем меньшее значение из двух.

Стоит отметить, что значения пропускной способности рассчитываются в разрезе одних суток, т.к. ремонтные работы имеют вполне определенные сроки, а изменение активного газа за одни сутки может значительно сказаться на потенциальных возможностях ПХГ. Особенно это актуально для ПХГ сравнительно небольших объемов и коротких циклах закачки/отбора газа.

\begin{tabular}{|c|c|c|c|c|c|c|}
\hline \multicolumn{7}{|l|}{ Ставропольское ЧПХГ. Режим отбора газа } \\
\hline Обозначение & Физ. размерность & 27.07 .2013 & 28.07 .2013 & 29.07 .2013 & 30.07 .2013 & 31.07 .2013 \\
\hline \multicolumn{7}{|c|}{ МАХпроизводительность горизонта Хадум по отбору газа } \\
\hline Горизонт Хадум. МАХпроизв-сть & $\mathrm{Nm}^{3} / \mathrm{d}$ & 17.000 .001 & 23.600 .001 & 0 & 23.600 .001 & 23.600 .001 \\
\hline \multicolumn{7}{|c|}{ МАХпроизводительность горизонта Зелёная Свита по отбору газа } \\
\hline Горизонт Зелёная Св. МАХпроизв-сть & $\mathrm{Nm}^{3} / \mathrm{d}$ & 67.000 .002 & 0 & 51.234 .563 & 34.000 .002 & 34.000 .002 \\
\hline \multicolumn{7}{|l|}{ Производительность по отдельным ГРП. Хадум } \\
\hline Хадум. ГРП 1. МАХпроизв-сть ГРП & $\mathrm{Nm}^{3} / \mathrm{d}$ & 800.000 & 3.000 .000 & 800.000 & 3.000 .000 & 3.000 .000 \\
\hline ГРП 1: состояние & & 1 & 1 & 1 & 1 & 1 \\
\hline Хадум. ГРП2. МАХпроизв-сть ГРП & $\mathrm{Nm}^{3} / \mathrm{d}$ & 3.000 .000 & 3.000 .000 & 800.000 & 3.000 .000 & 3.000 .000 \\
\hline ГРП 2: состояние & & 1 & 1 & 1 & 1 & 1 \\
\hline Хадум. ГРП З. МАХ произв-сть ГРП & $\mathrm{Nm}^{3} / \mathrm{d}$ & 3.000 .000 & 3.000 .000 & 800.000 & 3.000 .000 & 3.000 .000 \\
\hline ГРП 3: состояние & & 1 & 1 & 1 & 1 & 1 \\
\hline Хадум. ГРП 4. МАХ произв-сть ГРП & $\mathrm{Nm}^{3} / \mathrm{d}$ & 800.000 & 3.000 .000 & 800.000 & 3.000 .000 & 3.000 .000 \\
\hline ГРП 4: состояние & & 1 & 1 & 1 & 1 & 1 \\
\hline Хадум. ГРП 5. МАХ произв-сть ГРП & $\mathrm{Nm}^{3} / \mathrm{d}$ & 800.000 & 3.000 .000 & 800.000 & 3.000 .000 & 3.000 .000 \\
\hline ГРП 5: состояние & & 1 & 1 & 1 & 1 & 1 \\
\hline Хадум. ГРП 6. МАХ произв-сть ГРП & $\mathrm{Nm}^{3} / \mathrm{d}$ & 800.000 & 800.000 & 800.000 & 800.000 & 800.000 \\
\hline ГРП 6: состояние & & 1 & 1 & 1 & 1 & 1 \\
\hline Хадум. ГРП 7. МАХ произв-сть ГРП & $\mathrm{Nm}^{2} / \mathrm{d}$ & 800.000 & 800.000 & 800.000 & 800.000 & 800.000 \\
\hline ГРП 7: состояние & & 1 & 1 & 1 & 1 & 1 \\
\hline Хадум. ГРП 8. МАХ произв-сть ГРП & $\mathrm{Nm}^{3} / \mathrm{d}$ & 1.500 .000 & 1.500 .000[ & 1.500 .000 & 1.500 .000 & 1.500 .000 \\
\hline ГРП 8: состояние & & 1 & 1 & 1 & 1 & 1 \\
\hline Хадум. ГРП 9. МАХ произв-сть ГРП & $\mathrm{Nm}^{3} / \mathrm{d}$ & 1.500 .000 & 1.500 .000 & 1.500 .000 & 1.500 .000 & 1.500 .000 \\
\hline ГРП 9: состояние & & 1 & 1 & 1 & 1 & 1 \\
\hline Хадум. ГРП 10. МАХ произв-сть ГРП & $\mathrm{Nm}^{3} / \mathrm{d}$ & 800.000 & 800.000 & 800.000 & 800.000 & 800.000 \\
\hline ГРП 10: состояние & & 1 & 1 & 1 & 1 & 1 \\
\hline 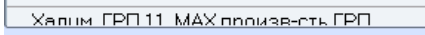 & $\mathrm{Nm}^{3} / \mathrm{d}$ & 8กก กกก & $8 \cap 0 \cap n+1$ & $8 \cap \cap ก \cap n$ & $8 \cap \cap ก \cap ก$ & $8 \cap \cap \cap \cap \cap-$ \\
\hline & & & $\rightarrow \Rightarrow$ & $\sqrt{-9}$ & 回 & 3акрыть \\
\hline
\end{tabular}


На рисунке 5 приведена сводная таблица рассчитанных производительностей по ПХГ в целом. Также в данной таблице указано состояние каждого из элементов системы. Это говорит о том, что диспетчер «одним кликом» вывести из расчёта целый комплекс, например ГРП.

Полученные значения и являются максимальной суточной пропускной способностью наземного технологического комплекса ПХГ с учётом потенциальных возможностей самого хранилища. Данные показатели применяются как, для поддержки принятия решений ДУ, так и при поддержке планирования режимов работы.

\section{6. Заключение}

Благодаря объединению разнородных источников информации нам удалось решить одну из очень важных задач при построении системы Диспетчерского управления ООО "Газпром ПХГ" - рассчитать пропускную способность наземного комплекса ПХГ с учётом различных влияющих факторов. Таким образом, сделав гибкий инструмент работы диспетчера, мы добавили к системе оперативнодиспетчерского управления функции поддержки принятия решений.

Дальнейшими перспективами проектного решения являются доработки в части улучшения точности расчёта, за счёт учёта менее значимых, но имеющих место факторов. Например, "ступенчатость" в работе оборудования.

\section{Список информационных источников}

[1] Левыкин Е. В. Технологическое проектирование хранения газа в водоносных пластах. - М.: Недра, 1973

[2] Брагинский О. Б. Нефтегазовый комплекс мира. - М.: РГУ нефти и газа имени И. М. Губкина, 2006.

[3] Бузинов С.Н. Подземное хранение газа. Полвека в России: опыт и перспективы. М.: ВНИИГАЗ, 2008.

[4] Томас Х. Кормен и др. Алгоритмы: построение и анализ. - 2-е изд. - М.: «Вильямс», 2006.

[5] Официальный сайт ОАО "Газпром", http://www.gazprom.ru.

[6] Бернер Л.И., Ковалёв А.А. Моделирование и прогнозирование режимов работы газотранспортных сетей системы поддержки принятия диспетчерских решений // Автоматизация и управление в технических системах. - 2012. - № 1. - С. 55-61.

[7] Бернер Л.И., Харитонов А.В., Харитонов М.В. Математические методы идентификации состояния трубы магистрального газопровода высокого давления // Автоматизация и управление в технических системах. - 2012. - № 2. - С. 103106.

[8] Белоусова А.И. Подход к формированию многоуровневой модели мультиагентной системы с использованием миваров / А.И. Белоусова, О.О. Варламов, М.Н. Краснянский, А.В. Остроух // Перспективы науки - Тамбов. «ТМБПринт», 2011. № 5(20). - С. 57-61.

[9] Варламов О.О. Анализ возможностей миварного подхода для систем искусственного интеллекта и современной робототехники / А.В. Остроух, М.Н. 
Краснянский, Т.Л. Давыдова, О.О. Варламов // Вестник ТГТУ. - 2011. - Т.17. - № 3. - C.687-694.

[10] Львова А.Б. Специфические требования при аутсорсинге IT-услуг в нефтехимическом производстве, возможные проблемы и варианты их решения / А.В. Остроух, К.А. Данчук, А.Б. Львова, Д.А. Павлов // В мире научных открытий. Серия «Проблемы науки и образования». - 2012. - №2.6 (26). - С.39-44.

[11] Николаев А.Б., Остроух А.В., Марсов В.И., Илюхин А.В. Сравнительный анализ систем экстремального регулирования процессов транспортирования нефтегазоводяной смеси // Современные наукоемкие технологии. - 2011. - № 3 стр. 35-39.

[12] Остроух А.В. Об одном походе к построению автоматизированной навигационной системы мониторинга и диспетчерского контроля и учета работы транспорта нефтедобывающих предприятий / А.В. Остроух, Д.Б. Ефименко, В.Н. Жучков // Инженер-нефтяник. - 2011. - №2. - С. 43-47.

[13] Остроух А.В. Мобильная установка для поверки узлов учета нефтегазоводяной смеси на местах добычи в нефтедобывающих предприятиях / А.В. Остроух, В.М. Власов, Д.Б. Ефименко, М.Н. Краснянский // Промышленные АСУ и контроллеры. - 2011. - №9. - С. 14-17.

[14] Остроух А.В. Инновационная установка для измерения количества нефти в составе нефтегазоводяной смеси на местах добычи / А.В. Остроух, А.Б. Николаев, В.А. Азовцев, В.Н. Жучков // Автоматизация, телемеханизация и связь в нефтяной промышленности. - М.: ОАО «ВНИИОЭНГ»,2011. - №11. - С.18-20.

[15] Остроух А.В. Разработка передвижной поверочной установки для выполнения поверки узлов учета нефтегазоводяных смесей / А.В. Остроух, А.Ю. Домогаров, А.Б. Николаев, В.Н. Жучков // Промышленные АСУ и контроллеры. - М.: «Научтехлитиздат», 2012. - №4. - С. 48-50.

[16] Остроух А.В. Системы экстремального регулирования процессов транспортирования нефтегазоводяной смеси / А.В. Остроух, А.В. Илюхин, В.И. Марсов, П.В. Замыцких // Приборы и системы. Управление, контроль, диагностика. - М.: «Научтехлитиздат», 2012. - №5. - С. 10-13.

[17] Остроух А.В. Основы построения систем искусственного интеллекта для промышленных и строительных предприятий: монография / А.В. Остроух. - М.: ООО «Техполиграфцентр», 2008. - 280 с. - ISBN 978-5-94385-033-2.

[18] Остроух А.В. Ввод и обработка цифровой информации: учебник для нач. проф. образования / А.В. Остроух. - М.: Издательский центр «Академия», 2012. - 288 с. - ISBN 978-5-7695-9457-1.

[19] Остроух А.В. Информационные технологии в научной и производственной деятельности / [ред. А.В. Остроух] - М: ООО "Техполиграфцентр", 2011. - 240 с. ISBN 978-5-94385-056-1.

[20] Остроух А.В. Системы искусственного интеллекта в промышленности, робототехнике и транспортном комплексе: монография / A.В. Остроух Красноярск: Научно-инновационный центр, 2013. - 326 с. - ISBN 978-5-90631410-9.

[21] Суркова Н.Е. Методы проектирования информационных систем / А.В. Остроух, H.Е. Суркова. - М.: PocHOУ, 2004. - 144 с. - ISBN 5-89789-021-8.

[22] Nickolayev A.B., Ostroukh A.V., Zamytskikh P.V., Gubanov A.I. Automated system of oil quantity and quality indexes estimation // EUROPEAN JOURNAL OF NATURAL HISTORY. - 2011. - № 3 - C. 96-98. 